\title{
Three-Dimensional Velocity Structure of the Upper Crust in the Hida Region, Central Honshu, Japan, and Its Relation to Local Seismicity, Quaternary Active Volcanoes and Faults
}

\author{
Takeshi Mikumo, ${ }^{1, *}$ Kazuro Hirahara, ${ }^{1, * *}$ Fumiaki Takeuchi, ${ }^{1}$ \\ Hiroo Wada, ${ }^{2}$ Tameshige Tsukuda, ${ }^{3}$ Iwao Fujii, ${ }^{4}$ \\ and Kin'ya Nishigami ${ }^{1}$ \\ ${ }^{1}$ Research Center for Earthquake Prediction, Disaster Prevention \\ Research Institute, Kyoto University, Uji 611, Japan \\ ${ }^{2}$ Kamitakara Geophysical Observatory, Disaster Prevention \\ Research Institute, Kyoto University, Gifu 506-13, Japan \\ ${ }^{3}$ Shin'etsu Seismological Observatory, Earthquake Research \\ Institute, The University of Tokyo, Nagano 380, Japan \\ ${ }^{4}$ Takayama Seismological Observatory, Faculty of Sciences, \\ Nagoya University, Takayama 506-01, Japan
}

The three-dimensional (3-D) velocity structure of the upper crust in the central part of the Hida region, central Honshu, Japan, has been investigated by simultaneous inversion of travel time data for velocity and hypocentral parameters using Thurber's method (1983). The data used for this purpose were 2,231 P-wave arrival times from 204 local earthquakes observed at 16 high-sensitivity seismograph stations. The iterative damped least-squares inversion used here provided reliable results with the diagonal elements of resolution matrix well exceeding 0.90 and standard errors less than $3 \%$ for the central area. The central part of the Hida region covering an extremely low seismicity area has high velocities probably extending down to a mid-crust. The high-velocity area composed of hard metamorphic and granitic complex extends from the western flank of the Hida mountains to the western section of the seismically active AtotsugawaUshikubi faults. The axial part of the Hida mountains and its southwestward area, on the other hand, is covered by remarkable low-velocities. The low velocities may be associated with a high thermal state due to active volcanism beneath the mountains involving volcanoes Mts. Tateyama, Yake, Norikura, and Ontake. The southwestern part of the Hida region is also partially covered by low-velocities beneath the Ryohaku mountains, which may also be related to volcanism of Mt. Hakusan. The obtained 3-D velocity structure appears to be qualitatively consistent with the Bouguer gravity anomalies and also with the large-scale 3-D structure so far obtained.

Received November 8, 1994; Accepted April 5, 1995

* Now at Instituto de Geofisica, Universidad Nacional Autonoma de Mexico (UNAM), Mexico 04510 D.F., Mexico

** To whom correspondence should be addressed. 


\section{Introduction}

The purpose of the present paper is to infer the 3-D velocity structure of the upper crust in the Hida region, central Honshu, Japan, by an inversion analysis of the observed travel times from a number of local earthquakes, and to discuss its possible relation to the distribution of Quaternary active volcanoes and faults and local seismicity.

The Hida region is located in a high mountain plateau in the northwestern part of central Honshu, Japan (Fig. 1). The highland region is bounded on the east by the Hida mountains which are the highest mountain range in Japan, on the west by the Ryohaku mountains, on the north by the Toyama plain, and on the south by the Mino mountain belt. The region is composed geologically mainly of Paleozoic-Mesozoic formations and partly of Tertiary-Quaternary volcanic rocks. The central part is covered by the Hida metamorphic and granitic complex (Early Mesozoic) and the Tetori group (Early Cretaceous). The Hida mountains located in the eastern part are composed of old granitic rocks (Paleozoic) and Triassic formations. The western and southern parts are covered by the Nohi rhyolite (latest Paleozoic and Cretaceous), while the northern part consists of Tertiary volcanic rocks and sediments (Geological Survey of Japan, 1978). The Hida mountains include four active volcanoes located from north to south: Mt. Tateyama (strato volcano with postcaldera lava flows), Mt. Yakedake (lava dome), Mt. Norikura and Mt. Ontake, the latter two being composed of strato volcanoes. Two active volcanoes are also located west of the Hida region: Mt. Hakusan (two strato volcanoes) and Mt. Dainichi.

The Hida region is characterized by a number of conjugate sets of Quaternary active faults. One of the fault systems consists of right-lateral, ENE-WSW to NE-SW

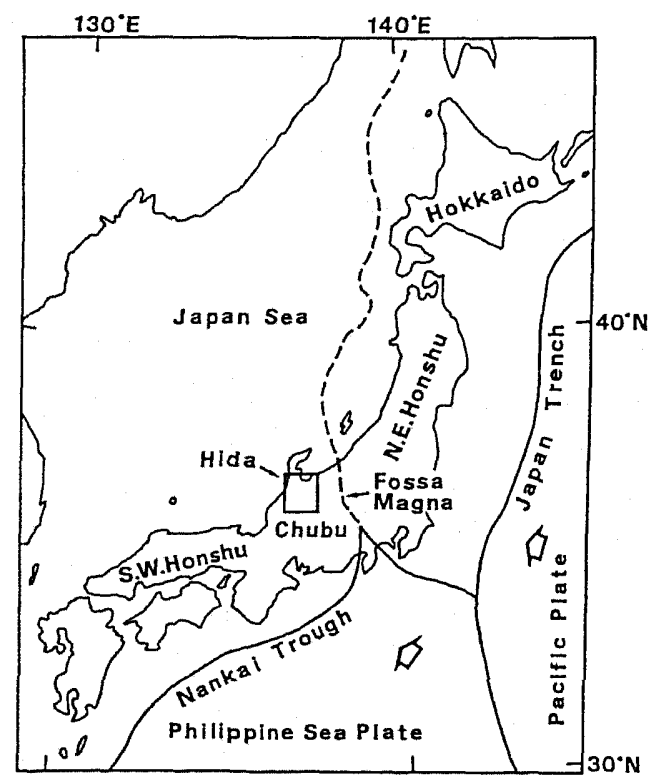

Fig. 1. Location of the Hida region, central Honshu, Japan. 


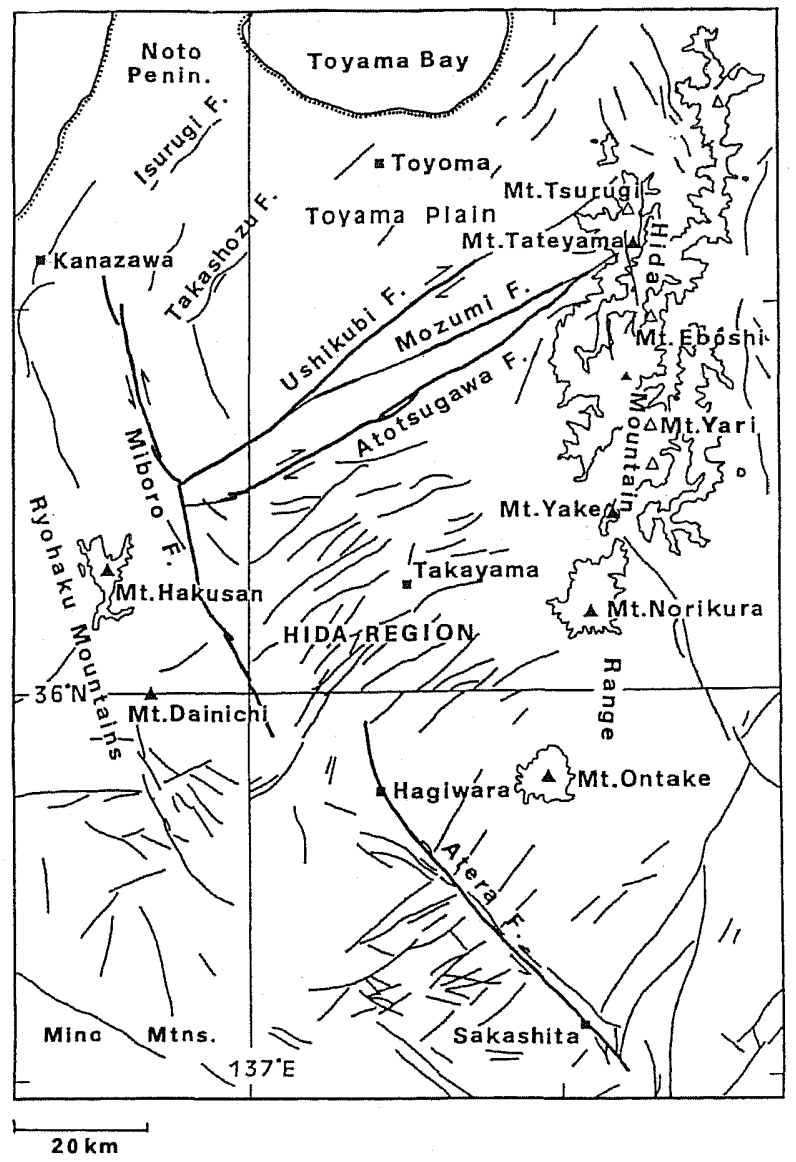

Fig. 2. Distribution of Quaternary active faults in the Hida region. Solid and open triangles indicate the locations of active volcanoes and high mountains, respectively, where contours around there indicate an elevation of $2,000 \mathrm{~m}$. Thin arrows along major faults show the direction of long-term strike-slip movement.

trending strike-slip faults, including the Atotsugawa, Ushikubi, and Mozumi faults and many minor parallel faults, while the other consists of left-lateral, NNW-SSE to NW-SE trending strike-slip faults, including the Miboro, Atera and several minor faults. The locations of all these faults and volcanoes are reproduced in Fig. 2 (Mikumo et al., 1988). The detailed topographical and geological features of the major faults including the long-term average slip rates and some evidence from paleoseismic trenching surveys have been summarized in the previous paper. The existence of the conjugate fault system suggests that the region has been subjected to strong compressive stress working in an ESE-WNW direction during the Quaternary period and hence that the upper crust may have considerable fractures. 


\section{Seismicity}

The existence of many Quaternary faults also suggests that a number of large earthquakes may have taken place in this region since around $1 \mathrm{~m} . \mathrm{y}$. , and there were actually several major historical earthquakes as described in Mikumo et al. (1988).

The present seismicity in the Hida region has been revealed by high-sensitivity seismic observations mainly made by the Kamitakara Geophysical Observatory, Kyoto University since 1977 in cooperation with the Takayama Seismological Observatory, Nagoya University, the Shin'etsu Seismological Observatory, Earthquake Research Institute, the University of Tokyo and the Hokuriku Microearthquake Observatory, Kyoto University. Figure 3 shows the spatial distribution of more than 5,800 local

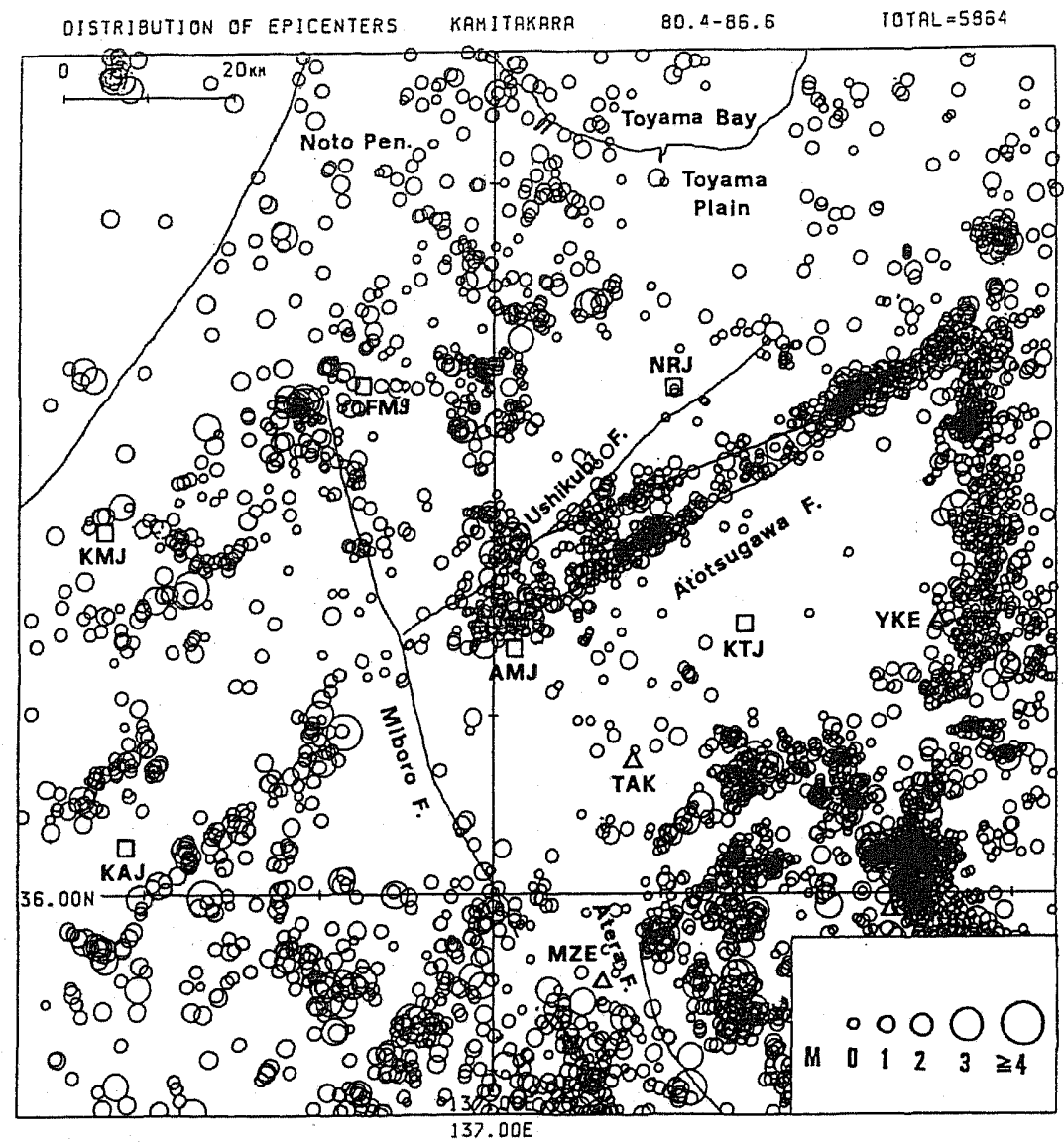

Fig. 3. Seismicity in the Hida region during the period from April, 1980 to June, 1986. Epicenters are classified by open circles of five different sizes indicating their magnitudes: $M>4.0,3.0<M<4.0,2.0<M<3.0,1.0<M<2.0$, and $M<1.0$. Solid squares and open triangles indicate seismograph stations, and thin solid lines indicate major Quaternary faults (Mikumo et al., 1988). 
earthquakes with magnitudes down to 0.5 over the Hida region for the period from April, 1980 to June, 1986 (Mikumo et al., 1988). These epicenters have been located by an iterative non-linear least-squares technique under a one-dimensional, horizontally layered structure, which had been derived from various seismic and geophysical observations (see Mikumo et al., 1988). The epicenters here are denoted by five different symbols according to their magnitudes indicated in the figure. The average probable errors estimated in these locations are less than $1.0 \mathrm{~km}$ in the horizontal direction and $2.0 \mathrm{~km}$ in the focal depth, within a distance of $25 \mathrm{~km}$ from the center of the network. The corresponding errors within the distances from 25 to $50 \mathrm{~km}$, however, are the order of 1.5 and $3.0 \mathrm{~km}$, respectively.

The seismicity map shown here indicates that there is a high concentration of seismicity along the Atotsugawa fault, with a clear lineation having active zones in the eastern and western sections and an intermittent zone of low activity. There are also belt-like concentrations of seismicity trending nearly in an N-S direction beneath the Hida mountain range, and block-like seismicity west of the southern part of the Hida mountains. On the other hand, a triangular region bounded on the northeast by the Atotsugawa fault and on the east by the Hida mountains, is a region of extremely low seismicity. There is also moderate seismicity west of the Toyama plain, although no seismicity has been detected in its central part (Mikumo et al., 1988).

\section{Observed Data Used for Inversion Analysis}

The observed data set used for our final inversion analysis comes from 204 local earthquakes with magnitudes greater than $M>3.0$, that occurred in the Hida region during the period from April, 1986 to August, 1987. We carefully selected these earthquakes to be distributed spatially as uniformly as possible, among a number of shocks shown in Fig. 3. The data have been obtained at the following 16 stations including 2 temporary stations: Kamiakara (KTJ), Amo (AMJ), Nirehara (NRJ), Fukumitsu (FMJ), Nanao (NNJ), Asahi (AHJ), Kamigahora (KHJ), and Kashimo (KSJ) [Kamitakara Observatory, DPRI, Kyoto University], Takayama (TAK), Yakedake (YKE), Takane (TKN), and Maze (MZE) [Takayama Observatory, Nagoya University], Matsukawa (MTU) and Nagano-Asahi (ASI) [Shin'etsu Observatory, ERI, the University of Tokyo], Komatsu (KMJ) and Katsuyama (KAJ) [Hokuriku Observatory, DPRI, Kyoto University]. The locations of these recording stations are shown in Fig. 4, where their spacing ranges between 20 and $40 \mathrm{~km}$. The area covered by the local shocks and stations is approximately $160 \mathrm{~km} \times 140 \mathrm{~km}$.

We finally use 2,231 P-wave arrival time data obtained at the above stations for the inversion analysis. Elevations for all the recording stations are incorporated in the inversion scheme, since the stations in this mountainous region are located at quite different altitudes ranging from less than 100 to $1,500 \mathrm{~m}$. All the data have a reading precision better than $2 / 100 \mathrm{~s}$ and have been corrected for the time delay $(0.02-0.08 \mathrm{~s}$ depending on the station) due to the telemetering data transmission system.

In addition to these data from local earthquakes, we refer to the data obtained from the 1978 Tedori quarry blasts $\left(\lambda=136^{\circ} 38^{\prime} 51^{\prime \prime} \mathrm{E}, \varphi=36^{\circ} 15^{\prime} 25^{\prime \prime} \mathrm{N}, H=350 \mathrm{~m}\right)$ (Watanabe and Fukui, 1980), which have been observed at 33 recording sites in the

Vol. 43, No. 1, 1995 


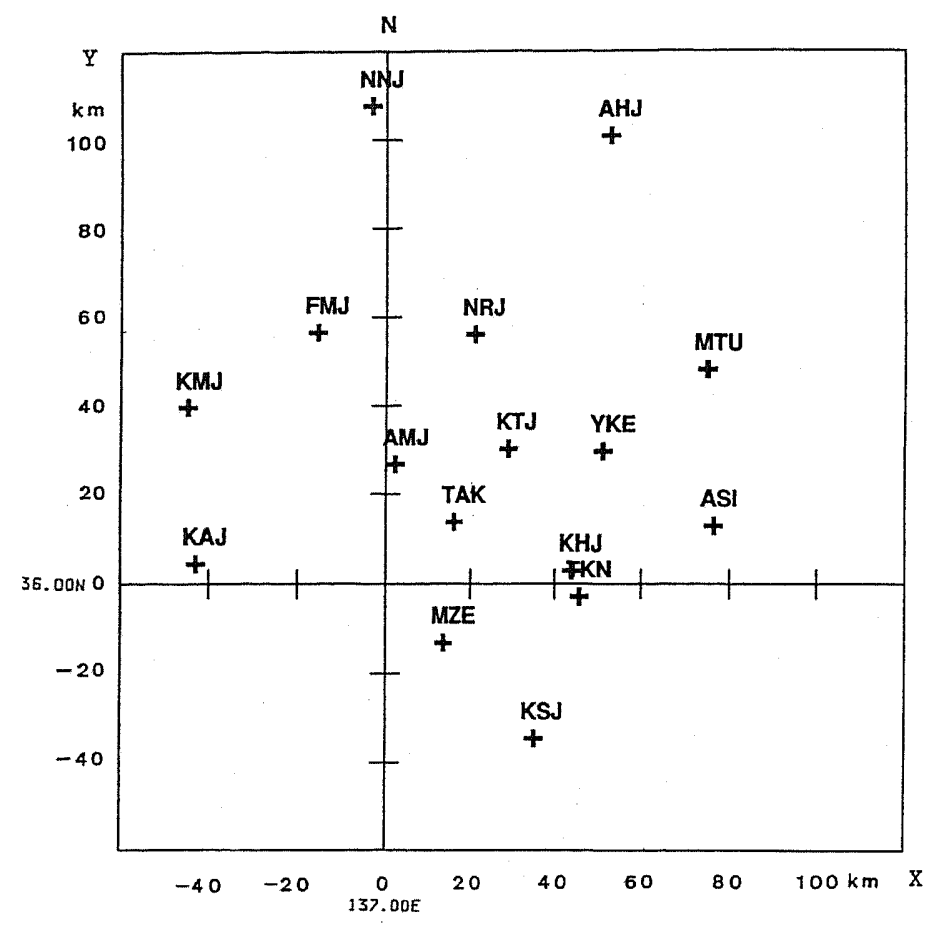

Fig. 4. Locations of seismic recording stations used for the present analysis.

distance range between 15 and $70 \mathrm{~km}$. The quarry blast data have been used to construct a one-dimensional starting velocity model, but were not directly incorporated into the inversion.

\section{Method of Travel Time Inversion}

In this paper, we apply Thurber's method $(1983,1993)$ of iterative damped least-squares inversion to the first $\mathrm{P}$-wave arrival time data described above to infer the general features of a 3-D velocity structure in the central part of the Hida region. This method allows simultaneous inversion of a 3-D velocity structure and hypocenter locations, using parameter separation and approximate ray tracing. The use of approximate 3-D ray tracing permits the treatment of laterally varying velocity structure and enables calculation of travel time residuals after each iteration, while parameter separation allows incorporation of a large amount of data (Thurber, 1983). The velocity structure is represented by interpolation of the velocity values obtained at discrete grid points set up in a 3-D space. The above method and more refined techniques (e.g., Zhao et al., 1992) have been successfully applied to reveal three-dimensional crustal structures in various tectonic regions including northern to southern California (Thurber, 1983; Eberhart-Phillips, 1986; Zhao and Kanamori, 1993; Eberhart-Phillips and Michael, 1993), the aftershock area of the 1984 Western Nagano earthquake in central Japan 
(Hirahara et al., 1992) and other regions. The results obtained to date are summarized in recent papers (Eberhart-Phillips, 1993; Foulger and Arnott, 1993).

The target region for our inversion covers an area of approximately $120 \mathrm{~km}$ $(\mathrm{E}-\mathrm{W}) \times 100 \mathrm{~km}(\mathrm{~N}-\mathrm{S})$, as shown in Figs. 3 and 4, and extends down to a depth of $12 \mathrm{~km}$ in the upper crust. For this area, we constructed two different model spaces covering the area (A) $-40 \mathrm{~km}<X<80 \mathrm{~km}$ and $-30 \mathrm{~km}<Y<70 \mathrm{~km}$, and (B) $-30 \mathrm{~km}<X<90 \mathrm{~km}$ and $-20 \mathrm{~km}<Y<80 \mathrm{~km}$, which are shifted relative to each other by $10 \mathrm{~km}$ both in the $X(\mathrm{E}-\mathrm{W})$ and $Y(\mathrm{~N}-\mathrm{S})$ directions, having an origin point $(X=0$ and $Y=0)$ at $\lambda=137^{\circ} 00^{\prime} \mathrm{E}$, $\varphi=36^{\circ} 00^{\prime} \mathrm{N}$. The grid spacing in the horizontal direction has been taken as $20 \mathrm{~km}$ considering the average spacing of the recording stations, and the grid in the depth direction has been set to be at $0,3,7$, and $12 \mathrm{~km}$, considering the $1-\mathrm{D}$ velocity structure in this region. The total number of the grid points thus selected is $7 \times 6 \times 4=168$ excepting those located at the side boundaries. The unknown parameters to be solved in the inversion are 168 velocity values at these grid points and 4 hypocenter parameters $(X$, $Y, Z$, and the origin time $T_{\mathrm{o}}$ ) of 204 local earthquakes. The final velocity structure at each depth is obtained by interpolating and smoothing two velocity values calculated for model spaces (A) and (B).

As a starting velocity model for the inversion, we adopted the 1-D horizontally layered velocity structure (Mikumo et al., 1988), which has been used for routine hypocenter location by the Kamitakara Observatory. The P-wave velocity in this model increases gradually from $5.4-5.7 \mathrm{~km} / \mathrm{s}$ above a $3 \mathrm{~km}$ depth to $6.0-6.3 \mathrm{~km} / \mathrm{s}$ in the depth range between 3 and $15 \mathrm{~km}$.

Thurber's (1983) approximate ray tracing assumes circular-arc ray paths for refracted waves connecting the source and receiver with the shortest travel time. This type of ray path is appropriate to a linearly increasing velocity model. However, this is a somewhat poor approximation for more general velocity structures, particularly at large distances where refracted waves are observed normally as the first arrival, since the path lengths would be overestimated and the angle of incidence would become steeper than that for the real ray path. To compensate for excessive bending of the ray paths, we incorporate a pseudo-bending ray technique (Thurber, 1993). In addition, we assign a smaller weight of $1 / 2$ to the arrival times of P-waves which have been observed at epicentral distances between 50 and $90 \mathrm{~km}$, and do not use the arrivals beyond $90 \mathrm{~km}$. This down-weighting on distant data would weaken hypocenter constraints to some extent.

The damping factor used to solve velocity values by the damped least-squares technique should be chosen based on an empirical approach. In the present case, we made several test calculations for damping factors of $0.2,0.5,1.0,2.0$, and 5.0, and finally selected 0.5 . This is because it was found that the data variance becomes stable for damping factors less than 2.0. Our calculations of iterative inversion reached a reasonable convergence after 4-6 iterations.

The resolution matrix gives an indication of how well the velocity is constrained at each grid point, which has a correlation with the number of ray paths passing near the grid point (Thurber, 1983). The diagonal elements of resolution matrix obtained here ranged between 0.45 and 0.99 for most of the grid points, except at the peripheries of the target area and at some of the deepest grids. The standard errors in the calculated 
velocities are in the range between 0.01 and 0.06 (fractional error) for the well-resolved cases. The data variance reduction in the solutions is $70 \%$ from 0.04 to $0.012 \mathrm{~s}^{2}$, and the final rms residual is found to be $0.073 \mathrm{~s}$.

\section{Hypocenter Relocations}

A preliminary inversion using 2,577 $\mathrm{P}$-wave arrival times from 237 shocks indicated that although most of the events in the central area were well constrained, some of the events located outside the perimeter of the network were found to be poorly constrained. For this reason, in the final inversion we excluded 33 events that moved from the original position by more than $6 \mathrm{~km}$ in its total distance. Accordingly, the number of data we actually used in the final inversion has been reduced to 2,231 from 204 shocks.

Figure 5 compares the epicenters calculated from the final inversion (indicated by open circles) with those determined by a routine procedure based on the 1-D horizontally layered structure (indicated by the positions of line heads). These lines indicate how much and to which direction the original epicenters were shifted by incorporating the 3-D laterally heterogeneous velocity structure. It may be immediately noticed that the epicenters located in the central area bounded approximately by $-10 \mathrm{~km}<X<80 \mathrm{~km}$ and $-10 \mathrm{~km}<Y<70 \mathrm{~km}$ are very well-constrained relative to those from the 1-D velocity

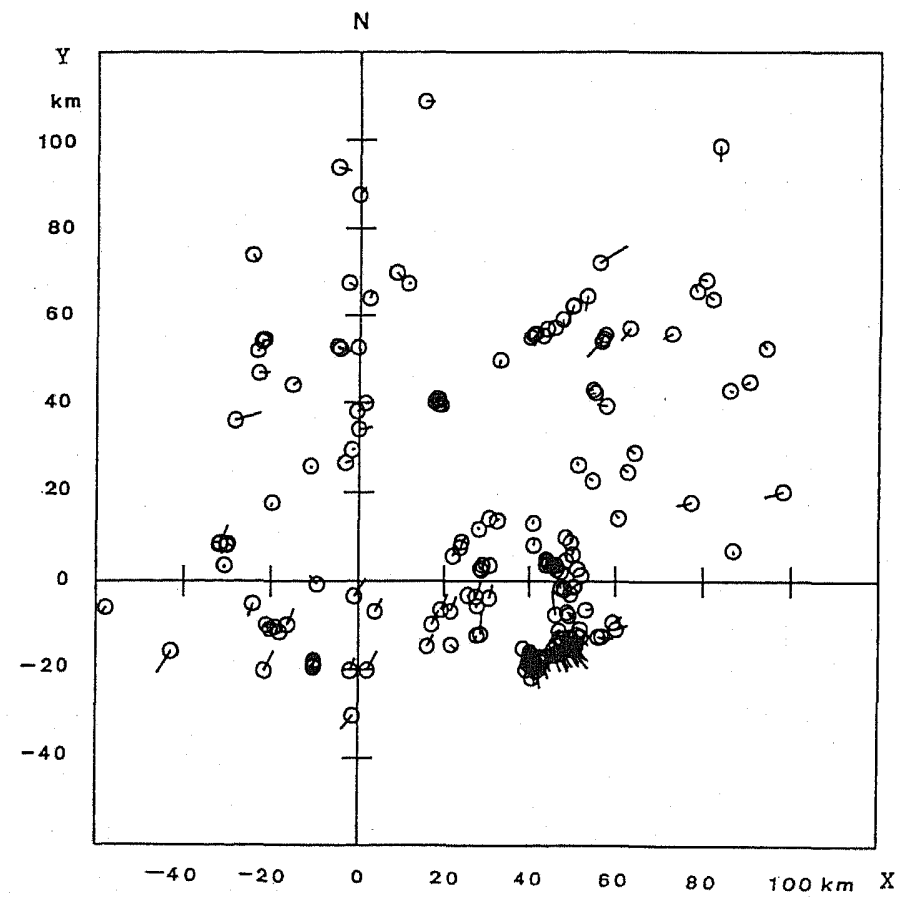

Fig. 5. Epicenters of 204 events, relocated from the 3-D inversion (open circles) and from a routine procedure based on the 1-D crustal structure (the positions of line heads). 


\section{X-PROJECTION}

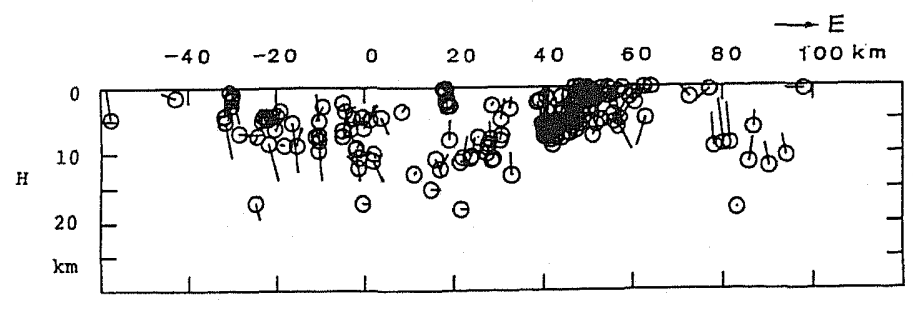

\section{Y-PROJECTION}

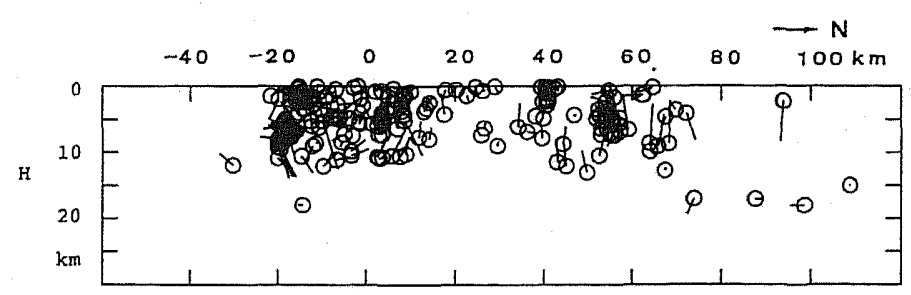

Fig. 6. Cross sections of hypocenter locations projected onto the vertical planes parallel to the $X$ - and $Y$-directions (vertical exaggeration: 1.5 times). The symbols used are the same as in Fig. 5.

structure. Figure 6 shows two cross-sections of these hypocenter locations projected onto two vertical planes parallel to the $X$ - and $Y$-directions, respectively. It is found that about $10 \%$ of the hypocenters moved upward or downward by 2 to $5 \mathrm{~km}$, but the vertical shift for the remaining events was less than $2 \mathrm{~km}$. Although the use of S-waves would provide more constraints, their high-quality data are not available at this moment.

As stated above, the hypocenter locations based on the 1-D model in the central part of the Hida region did not move significantly even if the 3-D velocity structure is taken into account. This implies that our previous discussion (Mikumo et al., 1988) on the local seismicity and its relation to Quaternary active faults in this region and to the Hida mountain range still remains valid, but that the epicentral locations and focal depths in the peripheral zones should be more carefully discussed.

\section{Three-Dimensional Structure}

The target area covers the region extending eastwards to the eastern foot of the Hida mountains, westwards to the western foot of the Ryohaku mountains, northwards to the Toyama plain, and southwards to the northern part of the Mino highland (see Fig. 2), for which a 3-D velocity structure has been obtained. Figure 7 shows straight lines connecting the relocated epicenters and receivers, indicating the density of the ray paths passing through each area in the target region. This density suggests that the 


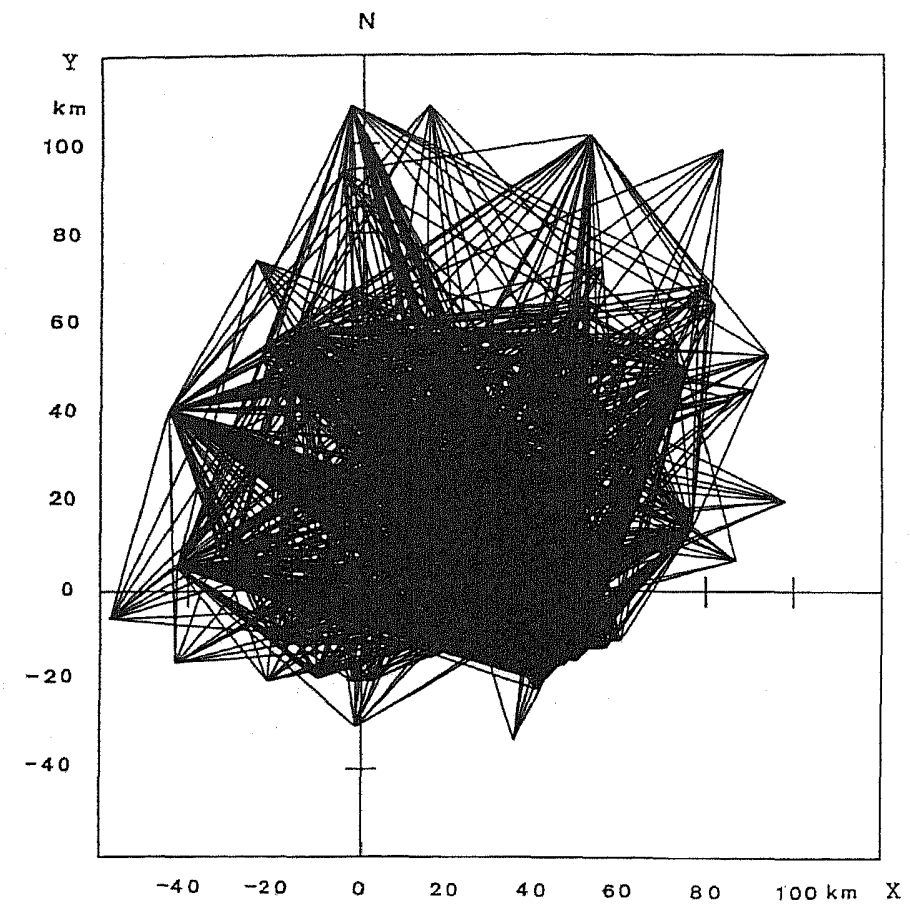

Fig. 7. Straight-line ray paths between the relocated epicenters and receivers.

calculated velocities may be well-resolved in the area confined by $-20 \mathrm{~km}<X<70 \mathrm{~km}$ and $-20 \mathrm{~km}<Y<60 \mathrm{~km}$. For the final velocity model, we decided to adopt only the velocity values with diagonal elements of resolution matrix greater than 0.90 and standard errors less than $3.0 \%$, taking into consideration the density of the ray paths shown in Fig. 7. This may be a conservative but robust estimate of the velocity structure.

The obtained velocity profiles at depths $H=0,3,7$, and $12 \mathrm{~km}$ are shown in Figs. $8,9,10$, and 11 , respectively, on which local seismicities in the depth ranges of $0<D<3 \mathrm{~km}, 3 \mathrm{~km}<D<7 \mathrm{~km}, 7 \mathrm{~km}<D<12 \mathrm{~km}$ and $12 \mathrm{~km}<D<20 \mathrm{~km}$ are superposed. The area of well-resolved velocities within the above criteria are enclosed by thin dotted lines. It is noteworthy that the velocity values calculated from the preliminary and final inversions differ within the standard errors in the indicated areas. The velocity structure is shown by contour lines, where solid and broken curves indicate velocities higher and lower than $6.0 \mathrm{~km} / \mathrm{s}$, respectively. We will not extend our discussion, with an equal weight, to the depth of $12 \mathrm{~km}$, because of the very limited area of well-resolved velocities. It is clear from these figures that the structure of the Hida region may be generally characterized by higher velocity zones in the central area and by lower velocity zones in the eastern, southeastern and southwestern areas. Figure 12 shows two cross-sections of the velocity profiles in the E-W direction at $Y=30 \mathrm{~km}$, and in the N-S direction at $X=30 \mathrm{~km}$, respectively. In the two sections, the hypocenters located within $\pm 10 \mathrm{~km}$ along the $X$ - or $Y$-directions are included. Now, we discuss some features of the velocity 


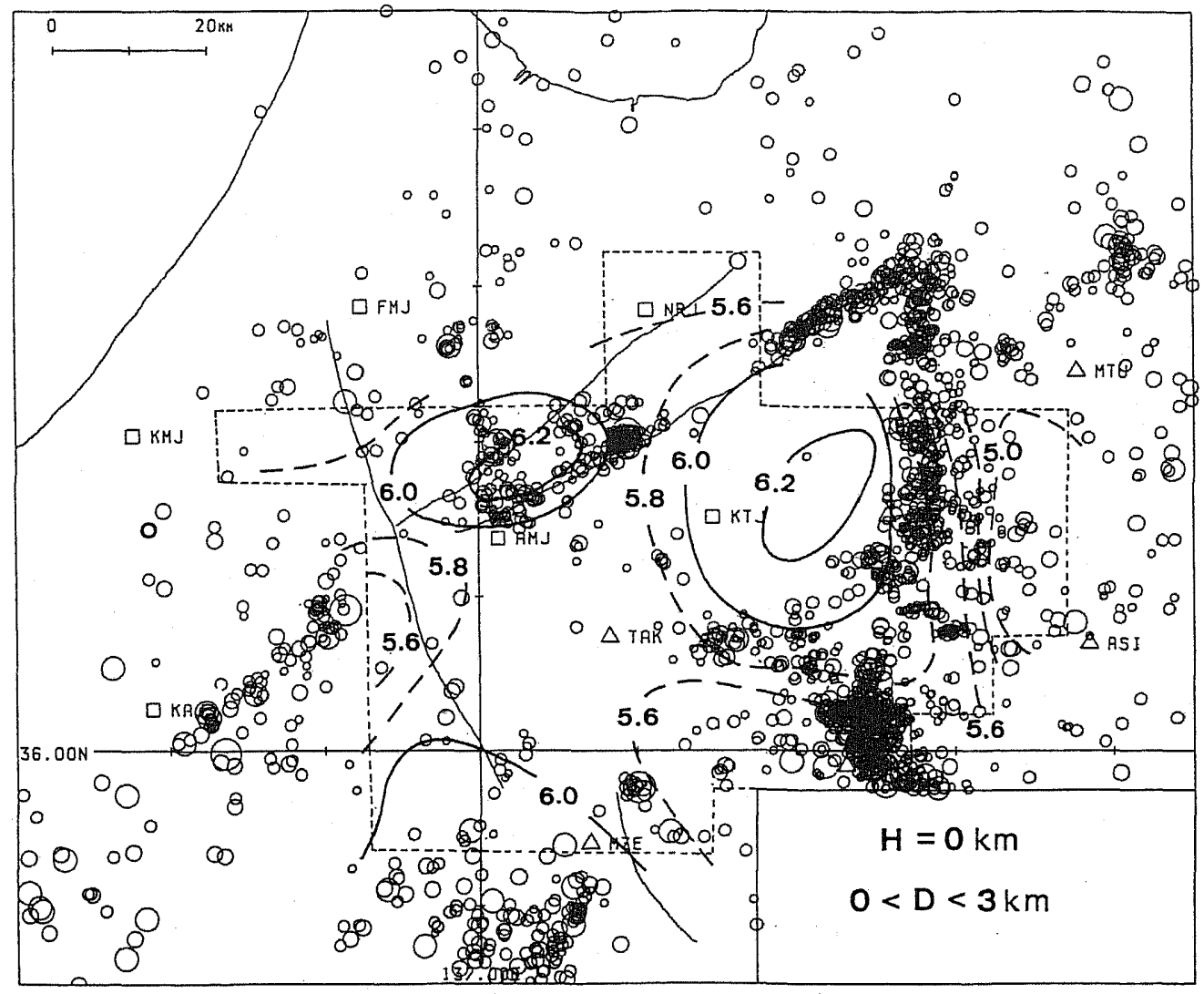

Fig. 8. Horizontal profile of the obtained 3-D velocity structure at the surface level $(H=0 \mathrm{~km})$, and seismicity in the depth range $0<D<3 \mathrm{~km}$. Thin dotted lines indicate the area of well-resolved velocities (with diagonal elements of resolution matrix exceeding 0.90 and standard errors less than $3.0 \%$ ). The same explanation applies to Figs. 9-11.

structure on the basis of the above figures, in relation to local seismicity and geological and topographical setting.

\subsection{Central area including the Atotsugawa fault}

In the central Hida region, there exists a high-velocity block with velocities of $6.0-6.2 \mathrm{~km} / \mathrm{s}$, which appears to cover almost the entire triangular area delineated by the Hida mountain range and the Atotsugawa fault. The eastern rim of the high velocity zone at shallow depths $(0-3 \mathrm{~km})$ reaches the western foot of the Hida mountains but appears to recede westwards at depths below $7 \mathrm{~km}$. The triangular zone is composed of the Hida metamorphic and granitic complex which is believed to be composed of hard rock materials. The obtained velocities may be associated closely with these hard rocks which do not involve minor faults or fissure cracks, and appears consistent with 


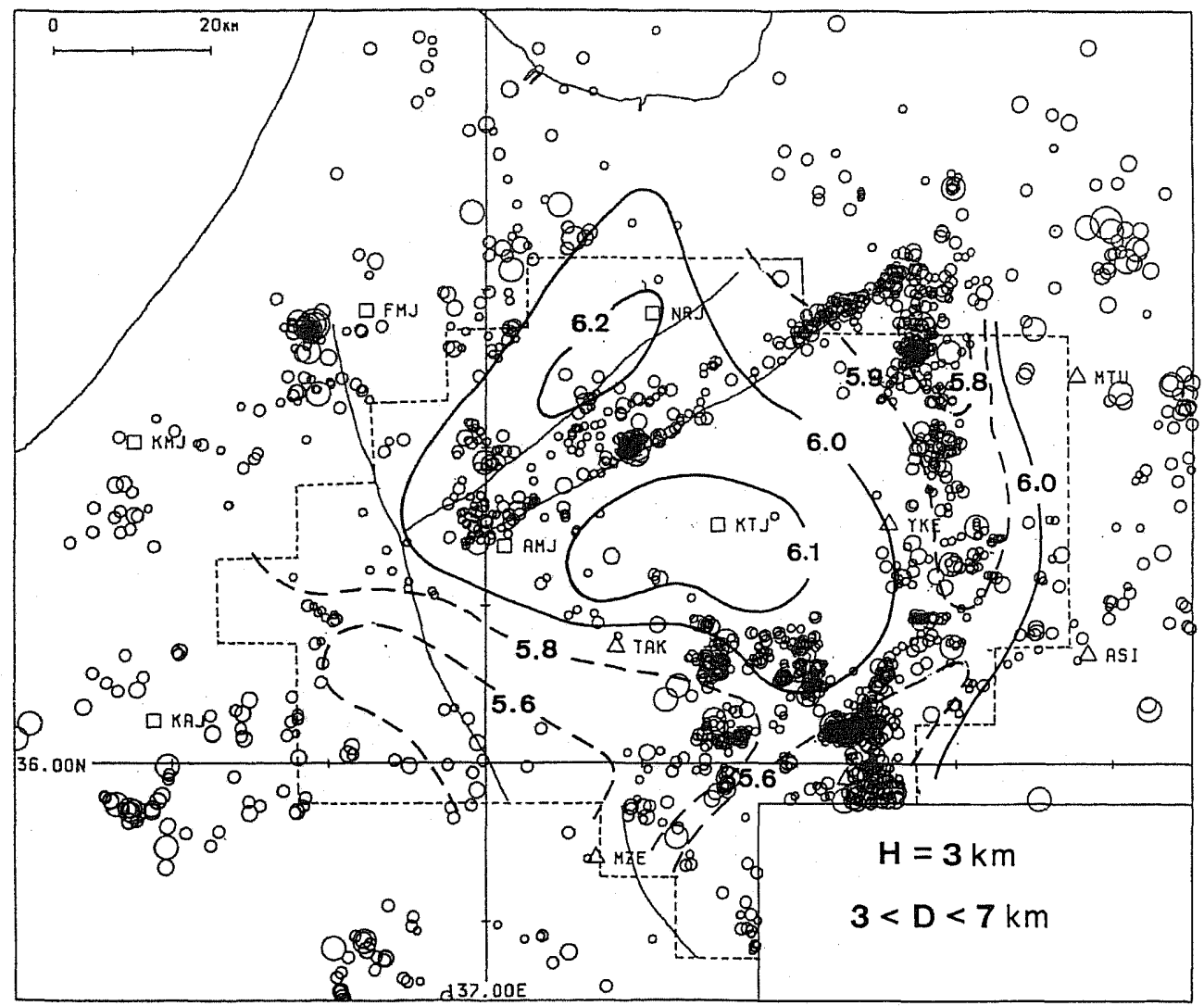

Fig. 9. Horizontal profile of the obtained 3-D velocity structure at the level of $H=3 \mathrm{~km}$, and seismicity in the depth range $3 \mathrm{~km}<D<7 \mathrm{~km}$.

very low seismicity in this zone. However, the high-velocity zone extends further northwards, penetrating to depths down to $7 \mathrm{~km}$, across the western sections of the Atotsugawa, Mozumi and Ushikubi faults, along which high seismicity. has been observed.

A possible interpretation for this situation would be that most of the central region represented by the high velocities had been originally composed of hard rock materials and that the faults were formed some time during the Quaternary period breaking this hard zone. Figure 12 suggests that the high-velocity zone extends down to at least $12 \mathrm{~km}$ in the central area. High seismicity along the Atotsugawa fault may be related to postseismic stress concentration after the 1858 Ansei-Hida earthquake $(M=7)$ that occurred probably due to the right-lateral strike-slip movement of the Atotsugawa fault. The seismicity bounded at a depth of about $15 \mathrm{~km}$ (Mikumo et al., 1988) may be confined within the high-velocity zone, although a detailed 3-D velocity structure at this depth has not been obtained. 


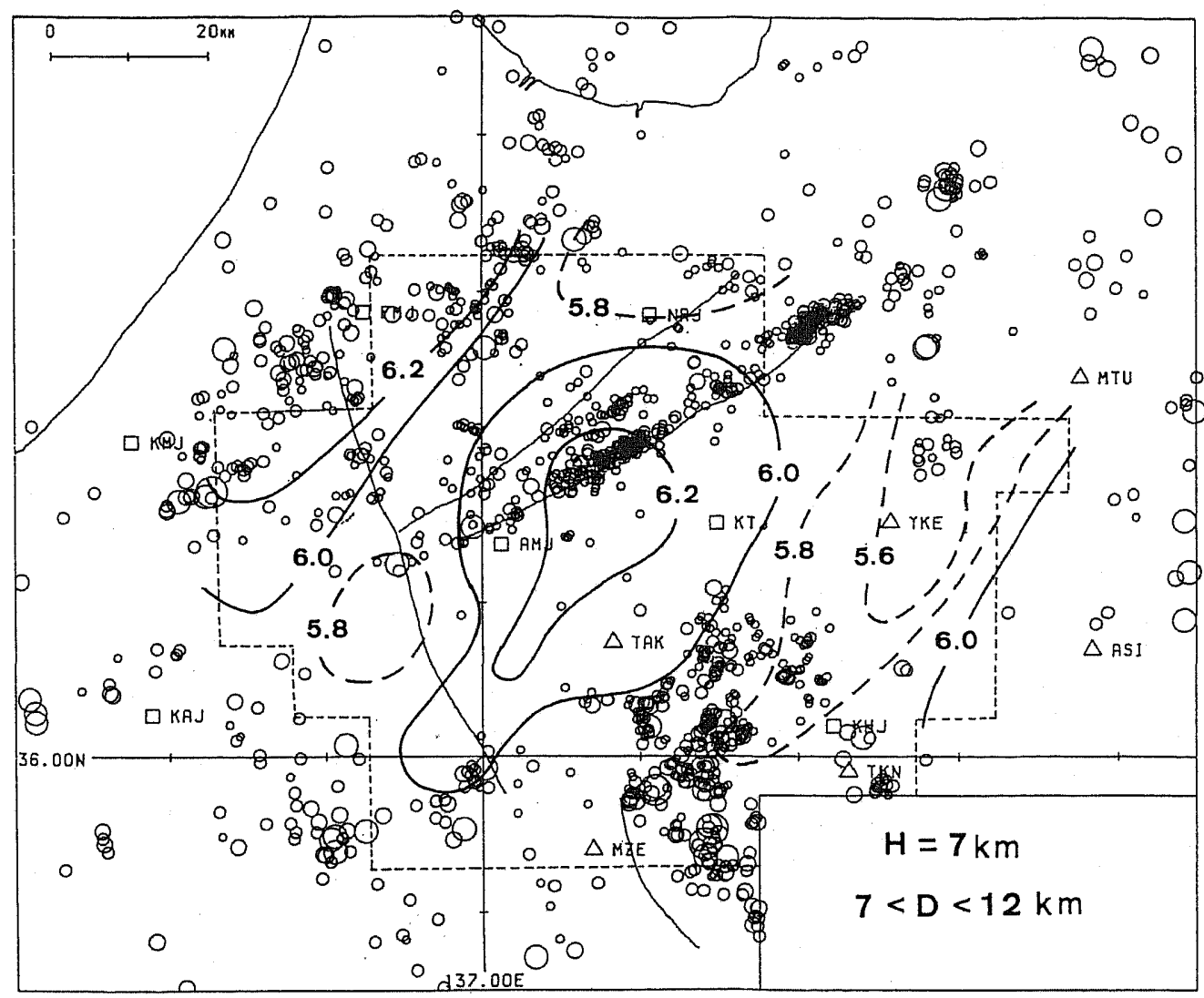

Fig. 10. Horizontal profile of the obtained 3-D velocity structure at the level of $H=7 \mathrm{~km}$, and seismicity in the depth range $7 \mathrm{~km}<D<12 \mathrm{~km}$.

\subsection{Around the Hida mountains}

It is most interesting to note that the axial part of the Hida mountain range trending in an N-S direction for about $80 \mathrm{~km}$ is generally covered by low velocities of $5.6-5.8 \mathrm{~km} / \mathrm{s}$ which appear to extend down to a depth of at least $7 \mathrm{~km}$, as seen from Figs. 8-10. Figures 8 and 9 indicate that the low-velocity zone at depths down to $3 \mathrm{~km}$ extends northwards covering the volcano Mt. Tateyama and the eastern section of the Atotsugawa fault, and southwards covering an active volcanic area including $\mathrm{Mt}$. Norikura and Mt. Ontake. The low-velocity zone at $7 \mathrm{~km}$ appears to extend westwards beneath a part of the triangular hard rock zone. The low velocities may be associated with a high thermal state due to active volcanism beneath the Hida mountains involving several volcanoes. Actually, surface heat flow measurements, which have been made at 12 sites within or very close to the northern section of the Hida mountains, indicate high thermal gradients in the range of $6^{\circ}-10^{\circ} \mathrm{C} / 100 \mathrm{~m}$, suggesting higher thermal conditions there (Mikumo et al., 1988).

It is also noteworthy that the high seismicity beneath the central to southern parts

Vol. 43, No. 1, 1995 


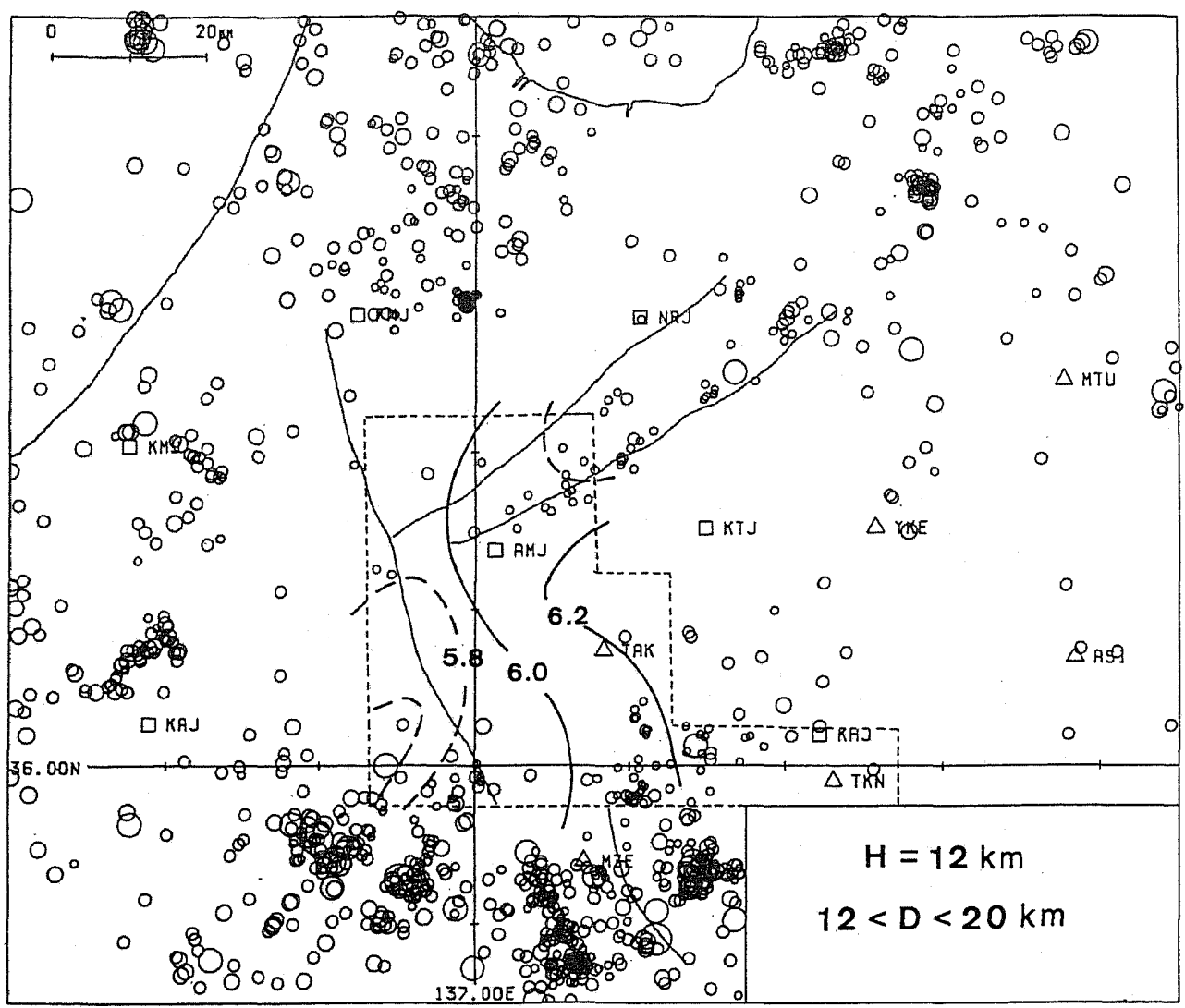

Fig. 11. Horizontal profile of the obtained 3-D velocity structure at the level of $H=12 \mathrm{~km}$, and seismicity in the depth range $12 \mathrm{~km}<D<20 \mathrm{~km}$.

of the Hida mountains is confined above $8 \mathrm{~km}$, which is significantly shallower than the seismicity beneath the Atotsugawa fault. An interpretation for the difference would be shallower transition from brittle to semi-brittle or ductile behaviors of rock materials due to higher temperatures (Mikumo, 1992) beneath the Hida mountains.

The area located west of the southern part of the Hida mountains is also covered by low velocities. The low velocities in this area might be attributed either to a westward extension of the high thermal zone from the volcanic area, or simply to the existence of Tertiary to Quaternary igneous rocks or of a number of minor faults there.

\subsection{Southwestern area}

As can be seen from Figs. 8-11, a low-velocity zone of $5.6-5.8 \mathrm{~km} / \mathrm{s}$ extends to a depth of $3 \mathrm{~km}$ over the area west of the Miboro fault and the Ryohaku mountains. These figures also indicate that the low-velocity zone penetrates down to $7 \mathrm{~km}$ around the active volcano Mt. Hakusan, suggesting that these low-velocities may also be associated with a high thermal state due to volcanism around there. There is almost 
(a)

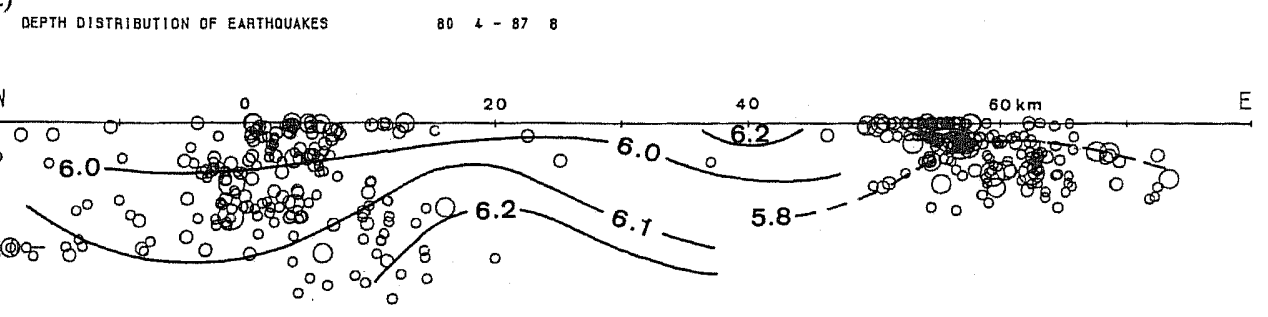

$20-$

(b)

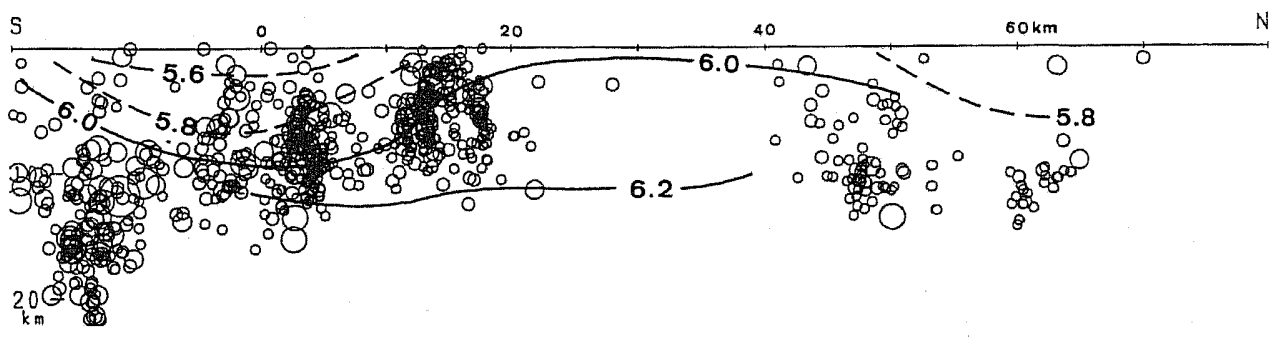

Fig. 12. Vertical cross sections of the 3-D velocity structure. (a) Along the E-W direction at $Y=30 \mathrm{~km}$. Seismicity in the range $Y=30+10 \mathrm{~km}$ is included. (b) Along the N-S direction at $X=30 \mathrm{~km}$. Seismicity in the range $X=30 \pm 10 \mathrm{~km}$ is included.

no seismicity below $7 \mathrm{~km}$ beneath $\mathrm{Mt}$. Hakusan, but no direct relationship can be detected between the cut-off depth of seismicity and the velocity structure over the area.

\section{Discussion}

\subsection{Comparison with a large-scale 3-D structure}

A large-scale 3-D velocity structure over central Japan has been investigated (Hirahara et al., 1989), using regional and local P-wave travel times observed at highsensitivity seismic stations, based on the method proposed by Aki and Lee (1976). The upper layer of the modeling space has been divided into a number of blocks with a size of $0.5^{\circ} \times 0.5^{\circ}$ and a thickness of $33 \mathrm{~km}$. For the thickness involving the entire crust and the large block size, the results obtained there do not have enough resolution to be compared directly with the present 3-D upper crustal structure. Nevertheless, it may still be interesting to look at their general features.

Figure 13 reproduces the velocity anomalies relative to the Jeffreys-Bullen standard velocity model, obtained for the northwestern part of central Honshu including the Hida region. The rectangular area enclosed by dotted lines indicates the target area in the present study. The overall features of the velocity structure are characterized by low-velocity anomalies over this region. The low anomalies are probably affected partly

Vol. 43, No. 1, 1995 


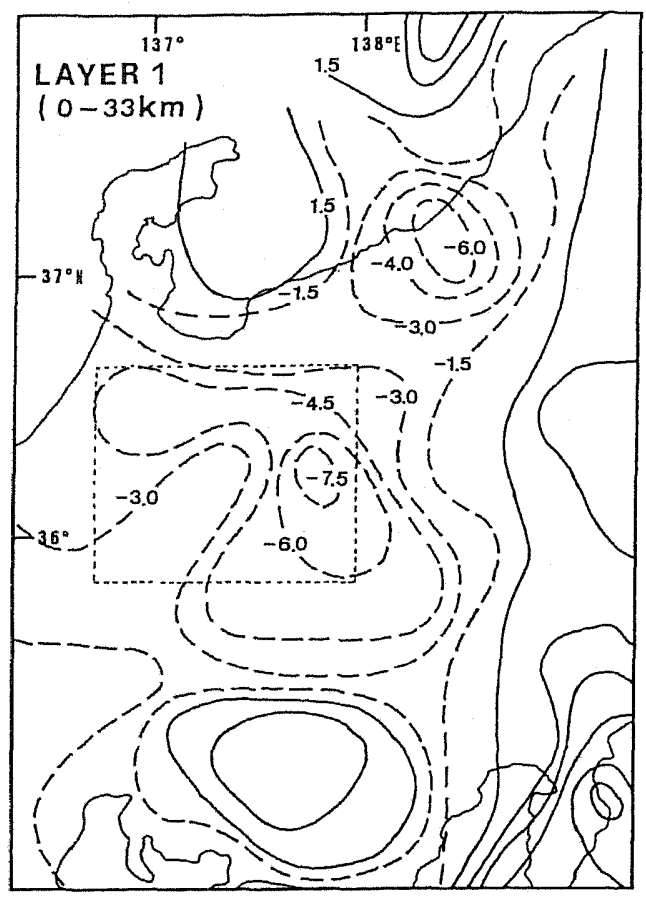

Fig. 13. A large-scale 3-D velocity structure in Layer $1(0-33 \mathrm{~km})$ in the northwestern part of central Honshu, Japan (Hirahara et al., 1989). Solid and broken contours indicate higher and lower velocity anomalies relative to the JeffreysBullen standard velocity model. Thin dotted lines indicate the target area in the present study.

by the low-velocity zones in the upper crust beneath the Hida and Ryohaku mountains and their surrounding areas, which have been detected from the present analysis, and this suggests the possible existence of low-velocity materials in the lower crust. The high-velocity zone in the central part of the Hida region may be confined above some depth around $12 \mathrm{~km}$, and appears to be bounded by low-velocity materials below this depth. Two vertical cross-sections $\left(36.0^{\circ}-36.5^{\circ} \mathrm{N} ; 137.5^{\circ}-138.0^{\circ} \mathrm{E}\right)$ of the velocity anomalies across the Hida mountains in the E-W and N-S directions are also reproduced in Fig. 14. A low-velocity body can be clearly identified in the crust just beneath the Hida mountains and beneath Mt. Hakusan, which appears to extend down to about $150 \mathrm{~km}$ in the upper mantle. The upper mantle low-velocity body may be a manifestation of higher temperatures, which would suggest the existence of partially melted diapirs around these depths (Ando et al., 1983).

\subsection{Comparison with gravity anomalies}

We compare the 3-D velocity structure obtained here with the distribution of Bouguer gravity anomalies in the central part of this region (Kono et al., 1982), which 

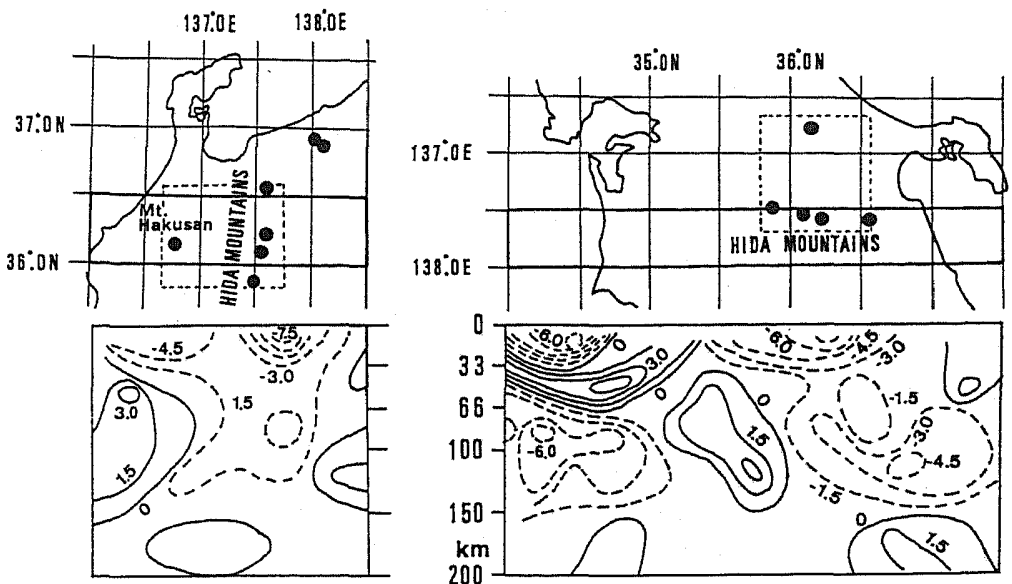

Fig. 14. Vertical cross-sections $\left(36.0^{d}-36.5^{\circ} \mathrm{N}\right.$ and $\left.137.0^{\circ}-137.5^{\circ} \mathrm{E}\right)$ of the large-scale 3-D velocity structure (Hirahara et al., 1989). Solid circles indicate the locations of Quaternary active volcanoes in this region.

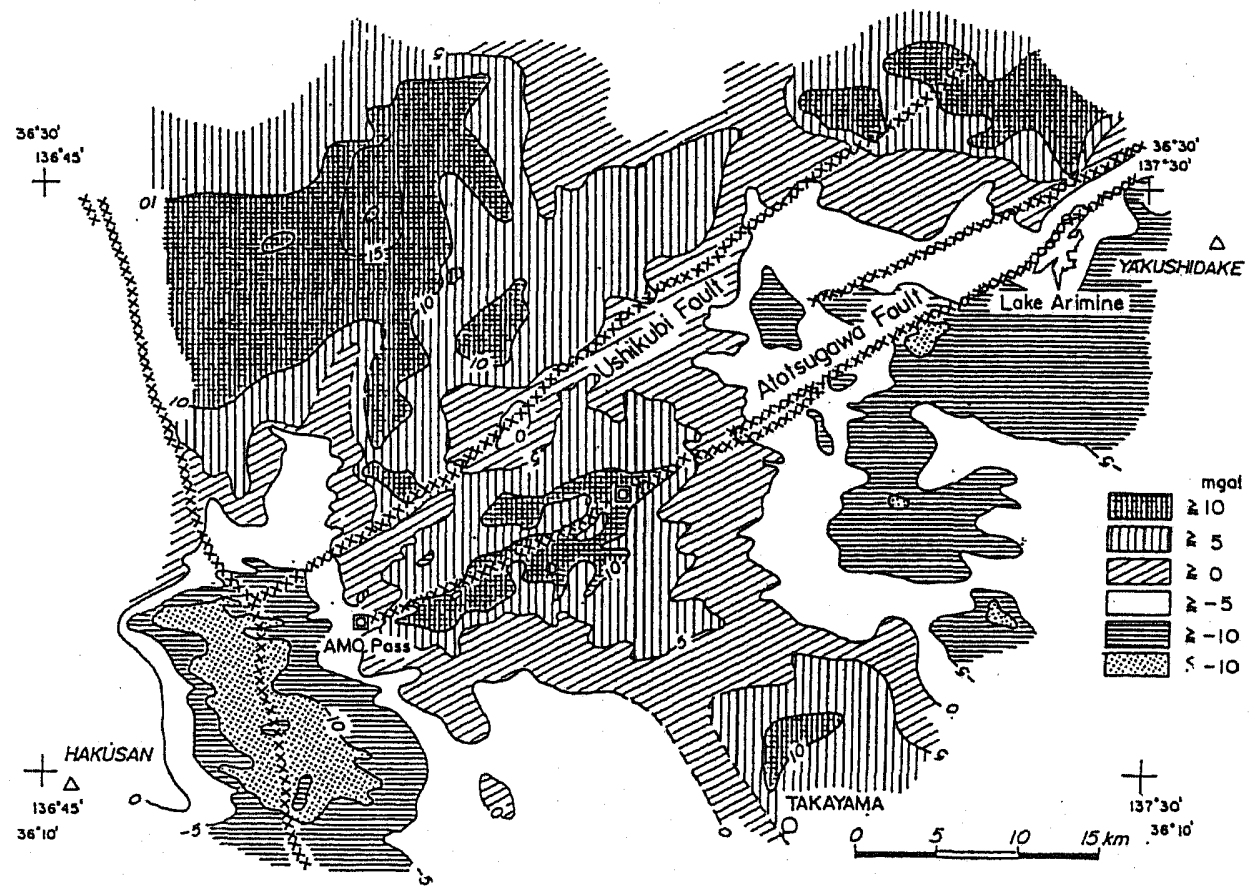

Fig. 15. Bouguer gravity anomalies around the Atotsugawa fault in the central Hida region (Kono et al., 1982).

Vol. 43, No. 1, 1995 
is reproduced in Fig. 15. There are moderate Bouguer anomalies in the central Hida region, particularly positive anomalies up to 10 mgals around the western part of the Atotsugawa fault. The anomalies appear to correspond to higher velocity zones covering the area. On the other hand, negative Bouguer anomalies down to -60 to $-80 \mathrm{mgals}$ (not shown here) have been detected along the axial portion of the Hida mountains. The negative anomalies may correspond at least qualitatively to the existence of the low-velocity zones extending down to the upper mantle. It also appears that the existence of the low-velocity body, covering the area from the west of the southern Hida mountains around Mt. Ontake to the Ryohaku mountains around Mt. Hakusan, is consistent with negative anomalies ( -40 to -60 mgals) there. However, all the above comparisons are only qualitative, and it is undoubtedly necessary to make more quantitative comparison on the relation in the seismic 3-D velocity structure and the distribution of Bouguer gravity anomalies, by incorporating a most probable relation between seismic velocity and material density.

\section{Conclusion}

We have investigated the general features of the 3-D velocity structure of the upper crust in the central part of the Hida region, Honshu, which is one of the tectonically and seismically most active regions in the Japanese Islands. The data used for this purpose were 2,231 P-wave arrival times from 204 local earthquakes observed at 16 high-sensitivity seismograph stations. We applied Thurber's simultaneous inversion method (1983) to the arrival time data to obtain a 3-D velocity structure and hypocentral locations. The iterative damped least-squares inversion used here yielded velocity values at about $70 \%$ of 168 grid points and $204 \times 4$ hypocentral parameters. These velocity values have been well resolved for the central area, with diagonal elements of the resolution matrix greater than 0.90 and standard errors less than $3.0 \%$.

The main conclusions we have obtained are as follows.

1) The central area of the Hida region covering an extremely low-seismicity zone has high-velocities of $6.0-6.2 \mathrm{~km} / \mathrm{s}$ extending down to at least $12 \mathrm{~km}$. The high-velocities, which may be a manifestation of hard rocks of metamorphic and granitic complex, extend from the western flank of the Hida mountains, northwestwards to the western section of the Atotsugawa-Ushikubi faults.

2) The axial part of the Hida mountains and its southwestward adjacent area is generally covered by low-velocities of $5.6-5.8 \mathrm{~km} / \mathrm{s}$. The low-velocities may be associated with high thermal state due to active volcanism beneath the Hida mountains involving several volcanoes, Mts. Tateyama, Yake, Norikura, and Ontake. High seismicity beneath the mountains is confined above $8 \mathrm{~km}$, which might be interpreted as coming from shallow transition from brittle to semi-brittle or ductile regimes of rock materials due to high temperatures.

3) The southwestern area of the region is also partially covered by low-velocities of $5.6-5.8 \mathrm{~km} / \mathrm{s}$ around the Ryohaku mountains. The low-velocities might also be associated with volcanism beneath Mt. Hakusan.

4) The general features of the obtained 3-D structure appears to be partly consistent 
with the large-scale 3-D velocity structure so far obtained and qualitatively consistent with the Bouguer gravity anomalies.

We thank the preliminary reviews on our manuscript provided by Eberhart-Phillips, Robert Geller, Akiko Hasemi, Hiroki Miyamachi and an anonymous reviewer. We are also grateful to the staff members of several institutions and observatories belonging to our universities, who allowed us to use the seismic data for the present study. The computations involved were made at the Data Processing Center of Kyoto University. The present study was partly supported by the Scientific Research Fund (No. B-6046005) provided by the Ministry of Education, Science and Culture of Japan.

\section{REFERENCES}

Aki, K. and W. H. K. Lee, Determination of three-dimensional velocity anomalies under a seismic array using first $\mathrm{P}$ arrival times from local earthquakes. 1. A homogeneous initial model, $J$. Geophys. Res., 81, 4381-4399, 1976.

Ando, M., Y. Ishikawa, and F. Yamazaki, Shear wave polarization anisotropy in the upper mantle beneath Honshu, Japan, J. Geophys. Res., 88, 5850-5864, 1983.

Eberhart-Phillips, D., Three-dimensional velocity structure in northern California coast ranges from inversion of local earthquake arrival times, Bull. Seismol. Soc. Am., 76, 1025-1052, 1986.

Eberhart-Phillips, D., Local earthquake tomography; earthquake source regions, in Seismic Tomography: Theory and Practice, ed. H. M. Iyer and K. Hirahara, pp. 613-642, Chapman \& Hall, London, 1993.

Eberhart-Phillips, D. and A. J. Michael, Three-dimensional velocity structure, seismicity, and fault structure in the Parkfield region, central California, J. Geophys. Res., 98, 15737-15758, 1993.

Foulger, G. R. and S. K. Arnott, Local tomography: volcanoes and the accretionary plate boundary in Iceland, in Seismic Tomography: Theory and Practice, ed. H. M. Iyer and K. Hirahara, pp. 644-675, Chapman \& Hall, London, 1993.

Geological Survey of Japan, Geological Map of Japan, 2nd ed., Geol. Surv., Japan, Kawasaki, Japan, 1978.

Hirahara, K., A. Ikami, M. Ishida, and T. Mikumo, Three-dimensional P-wave velocity structure beneath central Japan: low-velocity bodies in the wedge portion of the upper mantle above high-velocity subducting plates. Tectonophysics, 163, 63-73, 1989.

Hirahara, K. and the members of the 1986 joint seismological research in western Nagano Prefecture, Three-dimensional $\mathrm{P}$ and $\mathrm{S}$ wave velocity structure in the focal region of the 1984 western Nagano earthquake, J. Phys. Earth, 40, 343-360, 1992.

Kono, Y., T. Hibi, M. Kubo, O. Michigami, K. Shibuya, M. Sunami, K. Suzuki, and N. Furuse, Gravity anomaly over the northern part of the central Japan (1), Sci. Rep. Kanazawa Univ., 27, 71-83, 1982.

Mikumo, T., Dynamic rupture and stress recovery processes in continental crust under depthdependent shear strength and frictional parameters, Tectonophysics, 211, 201-222, 1992.

Mikumo, T., H. Wada, and M. Koizumi, Seismotectonics of the Hida region, central Honshu, Japan, Tectonophysics, 147, 95-119, 1988.

Vol. 43; No. 1, 1995 
Thurber, C. H., Earthquake locations and three-dimensional crustal structure in the Coyote Lake area, central California, J. Geophys. Res., 88, 8226-8236, 1983.

Thurber, C. H., Local earthquake tomography: velocities and $V_{\mathrm{p}} / V_{\mathrm{s}}$-Theory, in Seismic Tomography: Theory and Practice, ed. H. M. Iyer and K. Hirahara, pp. 563-583, Chapman \& Hall, London, 1993.

Watanabe, K. and H. Fukui, Upper crustal structure in the western Chubu district, Japan as derived from the Tedori-river quarry blasts, Bull. Disas. Prev. Res. Inst. Kyoto Univ., 30, 31-52, 1980.

Zhao, D. and H. Kanamori, The 1992 Landers earthquake sequence: earthquake occurrence and structural heterogeneities, Geophys. Res. Lett., 20, 1083-1086, 1993.

Zhao, D., A. Hasegawa, and S. Horiuchi, Tomographic imaging of $P$ and $S$ wave velocity structure beneath northeastern Japan, J. Geophys. Res., 97, 19909-19928, 1992. 